\title{
A Cross-Sectional Study on Perceived Stress and Coping Mechanisms among Children Suffering With Mute and Hearing Impairment
}

\author{
T. Sreedhar ${ }^{1}$, Dr. V. Srikanth Reddy ${ }^{2}$ \\ ${ }^{1}$ Ph.D Scholar, Department of Psychology, S.V.U, Tirupathi, India \\ ${ }^{2}$ Professor and Head, Department of Psychology, S.V.U, Tirupathi, India
}

\begin{abstract}
Background: Physically challenged children are the most vulnerable population in India. Among them mute and deaf children are gifted children with plethora of talents. In spite of having special abilities, this cohort has special needs. So far, studies have focused parental needs, stress, anxiety and depression of mute and deaf children. But very few studies has focused to study the stress, and coping strategies of mute and hearing impairment children. Therefore, the current study aims to study the stress and coping strategies of children suffering with mute and hearing impairment. Methodology: The current study adopted the descriptive research design and purposive sampling technique was followed. By following this technique the total of 60 school going children aged between 8-16 years suffering with mute and hearing impairment were included in the study. To measure the perceived stress, Stress Appraisal Measure (SAM) scale and to measure the coping strategies, coping strategies (CS) scale was used. The socio-demographic details were collected from school records. The descriptive statistics were used. Results: The results showed that the mean of children was12.23 \pm 2.70 . The results showed that children with special needs such as mute and deaf children had higher level of stress and decreased coping strategies. The majority of children $60 \%$ were male and $40 \%$ were female children participated in the study. About $96.7 \%$ hailed from rural back ground and least participants 3.3\% hailed from urban back ground. The result also showed that the majority $75 \%$ participants had partial hearing disability and the other 25\% children had complete hearing disability. The results also depicted that $100 \%$ children had associated mute disability besides either complete or partial hearing disability. The results also depicted that increased stress levels and decreased coping strategies among children with mute and deaf children. Conclusion and Implications: Therefore, we conclude that there is an urgent need to assess the psychological and social needs of children with mute and hearing impairment and address the mental health issues by providing psychological interventions for this cohort is imperative.
\end{abstract}

\section{Background}

Deafness is one of the disabilities seen in all age group. Deafness in younger age group is an emerging health problem in our country. There are 32 million $(9 \%)$ children in the world with disabling hearing loss (WHO 2012). Prevalence of deaf and mute children in India is 10.8 and 6.8 in rural and urban areas respectively (Jasmie 2013). Many researches were done on deaf-dumb children about their physical health, causes of deafness, cochlear implantation, degree of hearing loss, etc. Permanent childhood hearing impairment can have a devastating impact on communication skills, educational attainment, mental health and quality of life, with a high cost to society. Education of parents has also significant effect on development of the deaf children. Social problems were seen in the children with low education level of parents. Deaf children are more vulnerable to mental health problems than hearing children. The prevalence of mental health problems in community samples of deaf children is approximately $40 \%$ (Hindley.P 2000).

\section{Perceived Stress}

Stress is the body's reaction to a physical or emotional situation that causes imbalance in a person's life. Occasional stress is normal and predictable in our daily lives. Normal stress serves to present us with challenges for greater learning and opportunity, such as the stress that we may experience before meeting new people. On the other hand, constant stress can cause us many problems and, unless handled, can add to the stress of another situation. Children react in different ways to stress. Some children become ill. Some may become withdrawn and nervous while others show anger and demand attention. In some instances, development is affected. There are also some children who do not seem bothered by stress. We often call these children resilient. Stress becomes a problem when the ordinary stress of daily life becomes overwhelming. When under stress, there is an increase in heart rate, breathing is faster, and muscles tense up. When there are several stressors, the level and duration of the stress are greater (Honig, A.S.). Both negative and positive events can cause stress. Family events are often a source of stress for children .The breakup of a family is a negative event that can cause stress in children. Events such as physical abuse, separation, rejection, and fights are some other negative sources of stress. Other events such as a parent losing a job, or the death of a parent, grandparent, or siblingcan create stress. Positive events that cause stress in children include birthday parties, new pets, and the birth of new siblings. Everyday family obligations, events, and routines can create stress and tension for the young child, as in the case of an active family that may be so busy that the needs of a young child may be overlooked.(Ruffin \& Specialist, 2009).

Common signs of stress are listed below. These signs also may indicate that the child is experiencing problems other than stress. How do you identify stress from other problems that the child may be experiencing? First, parents and other caregivers must observe children's behavior. Children who isolate themselves from other children may be feeling stress. Also, the child who is easily agitated, irritable, lethargic, lazy, or aggressive may also suffer from stress. It is also 


\section{International Journal of Science and Research (IJSR) \\ ISSN (Online): 2319-7064}

Index Copernicus Value (2013): 6.14 | Impact Factor (2014): 5.611

important to watch the child for changes in habits or behavior (Ruffin \& Specialist, 2009)

How should you react when a child changes his or her normal behavior? Accepting the child's behavior is important. When one notices unusual behavior, having caring attitude towards the child, remain close to the child, and comfort the child may be useful (Ruffin \& Specialist, 2009)

Recognizing children's stress symptoms is not easy. It is very important to recognize that it is normal for children to exhibit some of these signs at some times in their lives. Adults need to be alert when a child is showing a cluster of these signs or symptoms simultaneously or when no apparent cause can explain why the child may be stressed. In either of these cases, it is a sign that the adults who are involved in the care of children need to intervene. If the child feels that it is impossible to handle the stress, he or she can become angry or aggressive. If the stress becomes too overwhelming for the child, then the child will experience anxiety. If the body remains in a state of anxiety, then physical, social, and emotional damage and deterioration can occur. The age of the child is a factor in recognizing stress. Children often cannot tell us what they feel or they do not have the language to describe the stressful situation (Ruffin $\&$ Specialist, 2009). Children react differently to stressful events and situations and also have different coping strategies. Children can cope through tears and crying, through tantrums, or by retreating from unpleasant situations. Children who are around supportive adults and caregivers usually develop a variety of coping strategies and are more likely to become more resilient. Many children, however, do not have a supportive environment and do not learn a set positive management strategies (Ruffin \& Specialist, 2009). Physiological or biological stress is an organism's response to a stressor such as an environmental condition or a stimulus. Stress is a body's method of reacting to a challenge. According to the stressful event, the body's way to respond to stress is by sympathetic nervous system activation which results in the fight-or-flight response. Because the body cannot keep this state for long periods of time, the parasympathetic system returns the body's physiological conditions to normal (homeostasis). In humans, stress typically describes a negative condition or a positive condition that can have an impact on a person's mental and physical well-being, (Selye, Hans). Another study showed that higher parental neuroticism, which reflects a susceptibility to emotional and psychological distress, complicated interaction between parents personality and stress related to child adjustment especially in deaf children(Plotkin, Brice, \& Reesman, 2014). In addition, low frequency information from a hearing aid, medium of medium of English teaching, cues of duration, absence of cues caused amplitude to perceived stress(Hegarty\& Faulkner, 2013). Studies reported that parents of young children may be more likely to succumb to impulsive reactions in attempting to arrest the crying, which could be a precipitating factor for child abuse, responding to physical stress as much as emotional stress (Calderon, Carney, \& Kavanagh, 2015).

\section{Coping Mechanisms}

Coping is essential to a full understanding of the effects of stress on children and adolescents because it not only depicts the individual's active role in the transactional process of dealing with the demands that adversity actually brings into a child's life, but also has the potential to consider how these ongoing encounters shape development. The effects of the coping power program with at-risk preadolescent boys at the time of transition from elementary school to middle school. Aggressive boys were randomly assigned to receive only the Coping Power child component, the full Coping Power Program with parent and child components, or a control condition. Results indicated that the Coping Power intervention produced lower rates of covert delinquent behavior and of parent-rated substance use at the 1-year follow-up than did the control cell, and these intervention effects were most apparent for the full Coping Power Program with parent and child components. Boys also displayed teacher-rated behavioral improvements in school during the follow-up year, and these effects appeared to be primarily influenced by the Coping Power child component Lochman \& Wells, (2004).

Snyder, C.R. Lefcourt, Herbert M. (2001) distinguished that there are various ways individuals deal with perceived threats that may be stressful. However, people have a tendency to respond to threats with a predominant coping style, in which they dismiss feelings, or manipulate the stressful situation. There are different classifications for coping, or defense mechanisms, however they all are variations on the same general idea: There are good/productive and negative/counterproductive ways to handle stress. Because stress is perceived, the following mechanisms do not necessarily deal with the actual situation that is causing an individual stress. However, they may be considered coping mechanisms if they allow the individual to cope better with the negative feelings/anxiety that they are experiencing due to the perceived stressful situation, as opposed to actually fixing the concrete obstacle causing the stress. Some research results also revealed that deaf students with greater degree of hearing loss and with bicultural skills that help them function in both the hearing and the Deaf community generally have higher self-esteem (Jambor \& Elliott, 2005).

There are ample number of problems have been reported their social life, behavioral changes, communication problems were reported but mental health related studies were very less conducted among children with mute and hearing impairment. Therefore, the current study focuses to understand the levels of perceived stress and coping abilities with suffering children, in particularly among mute and hearing impaired children.

\section{Methodology}

The study adopted the descriptive research design. All children suffering with hearing impairment were considered as the universe of the study. The present study was carried out between May to October 2015 at Victory Boarding School for Hearing impaired children at Settipalli in 


\section{International Journal of Science and Research (IJSR) \\ ISSN (Online): 2319-7064 \\ Index Copernicus Value (2013): 6.14 | Impact Factor (2014): 5.611}

Kuppam in Andrapradesh. It was run by Victory India Charitable Tent of Rescue Yacht. There were total of 60 students with hearing impairment enrolled in various classes and the participant's age was ranged between 8-16 years old, of which 36 students were boys and 24 students were girls. All were suffering from hearing impairment from mild to moderate. These 60 participants were recruited using convenient sampling technique. This sampling means selecting whatever sampling units are conveniently available. This method is also known as accidental sampling because the response whom the research meets accidently are included in the sample (Krishnaswamy 2005). All children with mute and hearing impairment aged between 8 to16 years, whose parents had given consent to participate in the study were included in the study. To measure the perceived stress, Stress Appraisal Measure (SAM) Scale, to measure the coping strategies, Coping Strategies (CS) Scale. The basic personal details and family details were collected from the school records. The data was collected in one to one interviews by using sign language by the researcher himself. Help was sought to clarify participant's queries from special educators who were teaching in the school in situations where researcher failed to communicate properly or additional clarification required. Prior permission was sought from school management and a brief 1 hour orientation was given to school management on the current research and purpose before the data collection. The ethical approval was sought from Sri ventkatewara University to carry out the study. The collected data was analysed using SPSS 20.00 version. For the continuous variables mean and standard deviation, for nominal and discrete variables frequency and percentage were calculated.

\section{Result}

The result showed that age of hearing impaired Children. The participant's age ranged from minimum 8 years to maximum 16 years. The average age was found to be $12.23 \pm 2.70$. The results showed that majority of children $60 \%$ were male and $40 \%$ were female children participated in the study. An half of the children $50 \%$ primary education and the other half $50 \%$ children were studying secondary education. The participant's majority $96.7 \%$ hailed from rural back ground and least participants 3.3\% hailed from urban back ground. The results showed all participants belong to Hindu religion. Of which, the majority $63.3 \%$ were living in joint family and just $37.7 \%$ was living in nuclear family. The result also showed that the majority $75 \%$ participants had partial hearing disability and the other $25 \%$ children had complete hearing disability. The majority $80 \%$ children had utilized residential facilities for their education and just $20 \%$ had been day scholars to access education. The results also depicted that $100 \%$ children had associated mute disability besides either complete or partial hearing disability.

The results revealed perceived stress of children with hearing impairment in various domains of perceived stress scale such as threat was (13.63 \pm 3.18$)$, challenge (13.55 \pm 3.58$)$, centrality(13.81 \pm 3.38$)$, control self-mean (13.48 \pm 3.53$)$, control others $(14.05 \pm 4.68)$, (Un-controllable $13.83 \pm 3.51)$ and stressfulness $(13.56 \pm 3.72)$. The total stress appraisal measure mean level of the was $(95.93 \pm 21.71)$. The results revealed that the mean of coping strategies (CS) in various domains of behavioural approach was (35.98 \pm 7.98$)$, cognitive approach (21.47 \pm 6.08$)$, cognitive-behavioral approach (19.03 \pm 6.08$)$, behavioral avoidance (46.30 \pm 5.66$)$, cognitive avoidance (16.86 \pm 3.66$)$. The overall all mean of coping strategies in $118.66 \pm 21.39$, among children with hearing impairment.

\section{Discussion}

The study investigated to measure perceived stress and coping strategies of person with hearing impairment and mute. The mental health issues of hearing impairment and mute children not much explored due to various physical and social problems. The current study found that majority of children age, average was between $8-16$ years. The male children who participated in the study $60 \%$ and $40 \%$ girl children and studying $50 \%$ primary education, $50 \%$ secondary education. Of which majority hailed from rural background. The second finding of the study was all participants and their families follow Hindu religion. The background characteristics such as age, educational and family details were comparable across schools in general in India(Augustine, Vazir, Rao, \& Rao, 2011)

The third finding of the study was $75 \%$ children suffering with partial disability, $25 \%$ children suffering with complete disability and followed by mutism was associated among all children. Hearing disability was found to be second most common disability in the current study $(21.95 \%)$. NSS 58th round 2002 also reported hearing disability as second most common type that at $16.56 \%$ (NSSO). Census 2001 reported hearing disability as least common type at $5.76 \%$. A hearing loss occurs when there is poor development, injury, infection or degeneration in any part of the hearing system. A hearing loss can be partial or total, temporary or permanent, in one ear (unilateral/monaural) or both(bilateral/binaural). A unilateral loss often goes unnoticed but may still have significant educational ramifications (Melanie Doyle et.al, 2002). The different terms such as disabled, handicapped, crippled, physically challenged, are used inter-changeably, indicating noticeably the emphasis on pathologic conditions (Centrl Statistical Organization(CSO), Office, Marg, \& Delhi, 2012).

The study found that more or less all children experienced perceived high levels of stress. The study observed that recognizing children's stress symptoms is not easy especially children with special needs. Low hearing aids, social stigma, medium of teaching, might have caused. The studies reported that children often cannot tell us what they feel or they do not have the language to describe the stressful situation (Ruffin \& Specialist, 2009) and higher parental neuroticism, which reflects a susceptibility to emotional and psychological distress, complicated interaction between parents personality and stress related to child adjustment especially in deaf children(Plotkin, Brice, \&Reesman, 2014).Adding to that low frequency information from a hearing aid, medium of English teaching, cues of duration, absence of cues caused amplitude to perceived stress(Hegarty\& Faulkner, 2013). Studies reported that parents of young children may be more likely to succumb to impulsive reactions in attempting to arrest the 


\section{International Journal of Science and Research (IJSR) \\ ISSN (Online): 2319-7064}

Index Copernicus Value (2013): 6.14 | Impact Factor (2014): 5.611

crying, which could be a precipitating factor for child abuse, responding to physical stress as much as emotional stress (Calderon, Carney, \& Kavanagh, 2015).

The study second findings also found that all children had poor level of coping skills. Numerous empirical findings also document its significance in various areas of research into deafness. Some of the research results on coping during childhood and adolescence is distinguished by its focus on how children deal with actual stressors in real life contexts. Despite burgeoning literatures within age groups, studies on developmental differences and changes have proven difficult to integrate. Two recent advances promise progress toward a developmental framework. First, dual-process models that conceptualize coping as "regulation under stress" establish links to the development of emotional, attention, and behavioral self-regulation and suggest constitutional underpinnings and social factors that shape coping development. Second, analyses of the functions of higherorder coping families allow identification of corresponding lower-order ways of Coping that, despite their differences, are developmentally graded members of the same family. This emerging framework was used to integrate 44 studies reporting age differences or changes in coping from infancy through adolescence. Together, these advances outline a systems perspective in which, as regulatory subsystems are integrated, general mechanisms of coping accumulate developmentally, suggesting multiple directions for future research (Skinner \& Zimmer-gembeck, 2007).

\section{Implications of the study}

The study highlighted that children with special needs particularly hearing and mute children. They perceived higher levels of stress, poor levels of coping skills. Hence, mental health professionals such as psychologists, medical and psychiatric social workers may initiate psychosocial intervention programmes to address the mental health of needs of hearing impairment and mute children with utmost care. Addition, school teachers and parents and care givers of children also should be educated how to understand the general needs and mental health needs by spending quality time with these children. The study had certain limitation such as children natural inability to express their needs, minimal knowledge of researcher in sign language in communicating with children, gender of the researcher were the limitations. Hence, generalization of these needs were cautioned.

\section{Conclusion}

There were high levels of stress and poor levels of coping skills were found. Therefore, there is an urgent need to address the psychosocial and mental health needs of institutionalized children by providing psychosocial interventions were emphasized. Thus, we conclude that working with hearing impairment and mute children the researcher should be with equipped communication skills especially in sign language a prior.

\section{References}

[1] Augustine, L. F., Vazir, S., Rao, S. F., \& Rao, M. V. V. (2011). Perceived stress, life events \& coping among higher secondary students of Hyderabad, India: A pilot study, (July), 61-68.

[2] Calderon, L. E., Carney, L. D., \& Kavanagh, K. T. (2015). The Cry of the Child and its Relationship to Hearing Loss in Parental Guardians and Health Care Providers. Journal of Evidence-Informed Social Work, 1-8. http://doi.org/10.1080/23761407.2015.1018031

[3] Fischer, M. E., Cruickshanks, K. J., Klein, B. E. K., Klein, R., Schubert, C. R., \& Wiley, T. L. (2009). Multiple sensory impairment and quality of life. Ophthalmic Epidemiology, 16(6), 346-353. http://doi.org/10.3109/09286580903312236

[4] Hegarty, L., \& Faulkner, A. (2013). The perception of stress and intonation in children with a cochlear implant and a hearing aid. Cochlear Implants International, 14 Suppl 4, S35-39. http://doi.org/10.1179/1467010013Z.000000000132

[5] Hindley P, Kitson N, Child and adolescent psychiatry, Mental health and deafness. London: Whurr's; 2000: 7598.

[6] Honig, A.S. (1986). Stress and Coping in Children. In J. McCracken's Reducing Stress in Children's Lives

[7] Jamie B. Deaf Community - India Rapidly Developing Deaf Community. http://deafness.about.com/od/internationaldeaf/a/indiadeaf. htm (accessed on 12 March 2013).

[8] Jambor, E., \& Elliott, M. (2005). Self-esteem and coping strategies among deaf students. Journal of Deaf Studies and Deaf Education, 10(1), 63-81. http://doi.org/10.1093/deafed/eni004

[9] Lochman, J. E., \& Wells, K. C. (2004). The coping power program for preadolescent aggressive boys and their parents: outcome effects at the 1-year follow-up. Journal of Consulting and Clinical Psychology, 72(4), 571-578. http://doi.org/10.1037/0022-006X.72.4.571

[10] Melanie Doyle, et.al (2002). MAINSTREAMING THE STUDENT WHO IS

[11] DEAF OR HARD-OF-HEARING. Manual for hard hearing children, CCHAT Centre, San Diego.

[12] National Sample Survey Organization (2002), Disabled Persons in India; Report No. 485 (58/26/1); NSS 58th round July — December 2002; Ministry of Statistics and Programme Implementation; Government of India; December.

[13] Plotkin, R. M., Brice, P. J., \& Reesman, J. H. (2014). It is not just stress: parent personality in raising a deaf child. Journal of Deaf Studies and Deaf Education, 19(3), 347357. http://doi.org/10.1093/deafed/ent057

[14] Ruffin, N. J., \& Specialist, E. (2009). Children and Stress : Caring Strategies to Guide Children.

[15] Selye, Hans (1974). Stress without distress. Philadelphia: J.B. Lippincott Company. p. 171.

[16] Skinner, E. A., \& Zimmer-gembeck, M. J. (2007). The Development of Coping. http://doi.org/10.1146/annurev.psych.58.110405.08570

[17] Snyder, C.R.; Lefcourt, Herbert M. (2001). Coping With Stress. New York: Oxford University. pp. 68-88.

[18] WHO global estimates on prevalence of hearing loss. Mortality and Burden of Diseases and Prevention of Blindness and Deafness WHO, 2012 